\title{
Staging in giant vestibular schwannoma surgery: A two consecutive day technique for complete resection in basic neurosurgical setups
}

\author{
Deepak Bandlish, Nilay Biswas, Sumit Deb \\ Department of Neurosurgery, Bangur Institute of Neurosciences, Kolkata, West Bengal, India
}

\begin{abstract}
Introduction: Vestibular schwannomas constitute $8 \%$ of all intracranial tumors. A majority of vestibular schwannomas are sporadic and unilateral. Giant vestibular schwannomas are seen in our country due to the late diagnosis and long duration of symptoms before diagnosis. These giant schwannomas are challenging to manage as most of the patients are having brainstem compression. Materials and Methods: Twelve cases of a giant vestibular schwannoma were operated in our department between May 2011 and December 2012. Vestibular schwannomas with a maximal diameter of more than $4 \mathrm{~cm}$ were defined as a giant vestibular schwannoma. All the patients had a unilateral vestibular schwannoma. Performance status of all the patients were graded as per the Karnofsky performance score. Pre-operative assessment of $5^{\text {th }}, 7^{\text {th }}, 8^{\text {th }}$ and lower cranial nerve status was done in all cases. Ventriculoperitoneal shunting was done pre-operatively in all cases. All patients were operated through retromastoid suboccipital craniectomy and retrosigmoid approach. These patients were operated in two stages in two consecutive days with overnight elective ventilation in ICU. Ultrasonic aspirator and nerve monitoring techniques were not used. Results: Giant acoustic schwannomas can be safely resected completely by a staged resection on two consecutive days without any increased morbidity or mortality. This technique may be employed to achieve complete resection of such lesions without deterioration of facial nerve function in institutions which do not have advanced facilities like nerve monitoring or ultrasonic aspirator.

Key words: Complete resection, developing country, giant vestibular schwannoma, staged surgery, two day consecutive technique
\end{abstract}

\section{Introduction}

Vestibular schwannomas constitute $8 \%$ of all intracranial tumors. ${ }^{[1]}$ A majority of vestibular schwannomas are sporadic and unilateral. The incidence is highest in Asian countries and various reports suggest an incidence rate of nearly $10 \% .{ }^{[2]}$ Giant vestibular schwannomas $(>4.0 \mathrm{~cm}$ in maximum diameter $)^{[3]}$ seen rarely in the west are seen more often in our country due to the late presentation and long duration of symptoms before diagnosis especially in socially and economically backward areas of eastern India.

\begin{tabular}{|l|l|}
\hline \multicolumn{2}{|c|}{ Access this article online } \\
\hline Quick Response Code: & Website: \\
\hline & www.ruralneuropractice.com \\
\cline { 2 - 2 } & \\
\hline
\end{tabular}

These giant schwannomas are challenging to manage as most of the patients have brainstem compression and score low on the karnofsky performance score ${ }^{[4]}$ It has been proven that complete tumor removal should be the goal of vestibular schwannoma surgery and maximum post-operative benefits can be expected in such cases..$^{[5]}$ Further, surgeries can get complicated due to incomplete hemostasis because of high tumor vascularity and indistinct planes of resection resulting in high morbidity and mortality more so with large tumors. ${ }^{[6-8]}$ Although various surgical techniques for operating on these tumors have been described, very few have discussed staged resection in these lesions. Staged resection also may vary as per the time interval between the stages. There are studies with 1- to 2-month interval between the stages..$^{[9]}$ The practice of pre-operative embolization of the tumor and definitive surgery 1 to 2 months later appears to be a viable option, but due to economical and logistical constraints in our set up it is more often than not, practically unfeasible. ${ }^{[10]}$ We present a series of 12 cases of

Address for correspondence:

Dr. Deepak Bandlish, Room no. 402, Junior Doctors Hostel, 242, AJC Bose Road, Kolkata - 700 020, West Bengal, India.

E-mail: deepak.bandlish@gmail.com 
giant vestibular schwannomas which were operated upon in two stages on two consecutive days in a government institute which although a tertiary referral centre for this area does lack advanced neurosurgical equipments like ultrasonic aspirator and nerve monitoring facilities. We believe that the goal of total removal of the tumor should take precedence and our technique might help other neurosurgeons in basic neurosurgical setups achieve the same.

\section{Materials and Methods}

\section{Study design}

This is an observational study conducted at Bangur Institute of Neurosciences Kolkata, India. Twelve patients with a giant vestibular schwannoma were operated upon in our department between May 2011 and December 2012. Vestibular schwannomas with a maximal diameter of more than $4 \mathrm{~cm}$ were defined as a giant vestibular schwannoma. Patients with a giant unilateral vestibular schwannoma, who were able to give a valid informed consent, were included in the study. Patients with Neurofibromatosis Type 2 (NF2) were excluded from the study. All patients were followed up for a minimum of 6 months.

\section{Functional work up}

Hearing was assessed by pure tone audiometry and speech discrimination scoring. Hearing function was graded according to Gardner Robertson scale which is the standard practice for assessment of preoperative hearing. ${ }^{[1]}$ Facial motor function was assessed using the House and Brackmann (HB) classification. ${ }^{[12]}$ Good results in facial motor function correspond to grades 1 and 2. ${ }^{[13]}$ Performance status of all the patients were graded as per the Karnofsky performance score. ${ }^{[4]}$ Pre-operative status of trigeminal nerve involvement with respect to motor and sensory function were assessed. All patients underwent pre-operative assessment of lower cranial nerve $(9,10,11$ cranial nerve) function.

\section{Radiographic workup}

Magnetic resonance imaging of brain with gadolinium contrast was done in all cases and tumor extent was graded according to Hannover classification system. ${ }^{[14]}$ Tumors were divided into various classes namely T1 (purely intrameatal), T2 (intra- and extrameatal), T3a (filling the cerebellopontine cistern), T3b (reaching the brain stem), T4a (compressing the brain stem) and T4b (severely dislocating the brain stem and compressing the fourth ventricle).

\section{Surgical technique and extent of resection}

Ventriculoperitoneal (Chhabra medium pressure) ${ }^{[15]}$ shunting was done 1 week pre-operatively in all cases.
All the patients were operated through retromastoid suboccipital craniectomy and retro-sigmoid approach. These patients were operated in two stages on two consecutive days. After the first day of surgery, patients were kept on mechanical ventilation overnight and excision of the remaining tumor was done next day in the morning. Facial nerve monitoring and Brainstem Auditory Evoked Response were not used during surgery. Tumor was excised under operating microscope using bipolar coagulation and suction irrigation. An ultrasonic aspirator was not used in any of the cases. Patients were shifted to ICU after a non-contrast computed tomography scan to rule out any hematoma on the first post-operative day. Tracheostomy was done in all cases intra operatively and subsequently removed before discharge in all cases. Histopathology revealed the schwannomas to be benign in all 12 cases.

Post-operatively patients were assessed at discharge, 1 month, 3 months and 6 months after discharge. Magnetic resonance imaging of brain with contrast was done in all cases at 6 months after discharge to measure the extent of resection in all cases.

\section{Results}

Age of the patients ranged from 36 to 68 years. There were seven $(58 \%)$ male patients and five (42\%) female patients. Nearly half of the patients belonged to the age group of 50 to 59 years [Table 1]. Duration of symptoms was 5 to 6 years in majority of patients. Hearing loss was the most common presenting symptom present in $12(100 \%)$ cases followed by headache present in $10(83 \%)$ cases. None of the patients had serviceable hearing. All patients had varying degrees of facial nerve paresis with eight patients having grade 2 paresis and four patients having grade 3 paresis. Obstructive hydrocephalus was present in all the 12 cases with clinical evidence of brainstem compression and fourth ventricle distortion present in $4(33 \%)$ cases. Vestibular symptoms were present in eight $(66 \%)$ of the cases. Three $(25 \%)$ cases had pre-operative lower cranial nerve dysfunction. Trigeminal dysfunction was also present in three cases in the form of ipsilateral facial sensory loss. Cerebellar signs were seen in $50 \%$ (6 of the 12) cases at presentation. Karnofsky performance score was low for most of the

Table 1: Demographic profile of the patients

\begin{tabular}{lccc}
\hline Age (years) & Male & Female & Total $(\%)$ \\
\hline $30-39$ & 3 & & $3(25)$ \\
$40-49$ & 1 & & $1(8)$ \\
$50-59$ & 3 & 3 & $6(50)$ \\
$60-69$ & - & 2 & $2(17)$ \\
\hline
\end{tabular}


cases. Almost all patients were bed ridden scoring between 50 and 70 on the index [Table 2].

Five patients had right-sided tumor and the remaining 7 had left-sided tumor. Grading of the tumors was done according to the Hannover MRI grade in case of all 12 patients. As seen in Table 3, all patients in the study were found to be having grade 4 tumors with eight patients presenting with grade $\mathrm{T} 4 \mathrm{~b}$ and four patients with grade T4a.

\section{Post-operative analysis}

Complete macroscopic tumor excision was done in all the cases [Figures 1 and 2]. Post-op CSF leak was not seen in any of the cases. Two patients developed post-operative meningitis which was managed by intravenous antibiotics. None of the patients developed post-op hydrocephalus presumably because they had undergone placement of a ventriculoperitoneal shunt in the pre-operative period. Two cases developed seizures in the post-operative period. There was no incidence of post-operative hematoma formation. Lower cranial nerve paralysis was seen in four $(25 \%)$ cases. However, 3 of these had lower cranial nerve dysfunction in pre-operative evaluation. Pre-operatively three patients had ipsilateral facial sensory loss. It was seen in six $(50 \%)$ patients in immediate post-operative period [Table 4]. Pre-operatively eight patients had House and Brackmann grade 2 facial palsy and four patients had grade 3 facial palsy. At discharge six patients had grade 2 facial palsy, four patients had grade 3 and two patients had grade 4 facial palsy. However, at 6-month follow up it was seen that six patients had grade 1 facial palsy, four patients had grade 2 palsy and two patients had grade 3 facial palsy. Trigeminal dysfunction improved over a 6-month period with only two cases having persistent facial sensory loss.
Serviceable hearing was present in none of the cases and post-operatively there was no improvement in hearing in any of the cases. Lower cranial nerve palsy improved in all cases at 6-month follow up. Patients with LCN palsy were fed through a Ryles tube for a prolonged period and oral feeding was started after assessment at 3-month follow-up visit. Eventually, all patients were able to have normal oral intake. The Karnofsky performance index showed improvement in all cases and most of the patients who were bed ridden at presentation were able to mobilize and take care of themselves [Table 5].

\section{Discussion}

In the past few years, the development of microsurgical techniques, the advent of new radiological diagnostic procedures, and intraoperative neurophysiological monitoring has helped us achieve a better management of vestibular schwannomas. ${ }^{[3]}$ The goals of surgery in case of small or medium sized tumors are preservation of facial nerve function and hearing whereas for larger lesions compressing the brainstem, the goals are radical removal with preservation of facial nerve function without additional morbidity ${ }^{[16]}$ In our setting, giant vestibular schwannomas are a very common presentation. Inadequate screening and referral systems account for delayed presentation resulting in poor prognosis. Radio surgery is not recommended for large lesions $(>3.5 \mathrm{~cm})$ associated with significant compression of the brainstem. These tumors usually require surgical resection. ${ }^{[17]}$

Small and medium sized tumors are often completely removed but such complete resection is much more difficult to achieve in large and giant vestibular schwannomas. ${ }^{[16]}$ Incomplete excision leads to a high

Table 2: Clinical profile of the patients

\begin{tabular}{|c|c|c|c|c|c|c|c|c|c|c|}
\hline Case & $\begin{array}{c}\text { Serviceable } \\
\text { hearing" }\end{array}$ & Headache & $\begin{array}{c}\text { Facial nerve } \\
\text { paresis }^{\star}\end{array}$ & $\begin{array}{l}\text { Vestibular } \\
\text { signs }\end{array}$ & $\begin{array}{l}\text { Riasedict } \\
\text { features }\end{array}$ & Tinnitus & $\begin{array}{c}\text { Lower } \\
\text { cranial nerve } \\
\text { dysfunction }\end{array}$ & $\begin{array}{c}\text { Trigeminal } \\
\text { nerve } \\
\text { dysfunction }\end{array}$ & $\begin{array}{l}\text { Cerebellar } \\
\text { signs }\end{array}$ & $\begin{array}{c}\text { Karnofsky } \\
\text { performance } \\
\text { index }\end{array}$ \\
\hline 1 & - & + & $+(2)$ & + & - & + & - & - & - & 60 \\
\hline 2 & - & + & $+(3)$ & + & + & - & + & + & + & 60 \\
\hline 3 & - & + & $+(3)$ & - & + & - & - & - & - & 70 \\
\hline 4 & - & + & $+(2)$ & - & + & + & - & - & + & 60 \\
\hline 5 & - & + & $+(2)$ & + & - & + & - & - & - & 60 \\
\hline 6 & - & - & $+(2)$ & + & - & - & - & - & + & 70 \\
\hline 7 & - & + & $+(2)$ & + & - & + & - & + & + & 60 \\
\hline 8 & - & + & $+(2)$ & - & - & - & + & - & - & 70 \\
\hline 9 & - & + & $+(3)$ & - & + & - & - & - & + & 60 \\
\hline 10 & - & - & $+(2)$ & + & - & + & - & + & + & 70 \\
\hline 11 & - & + & $+(3)$ & + & - & + & - & - & - & 60 \\
\hline 12 & - & + & $+(2)$ & + & - & + & + & - & - & 60 \\
\hline
\end{tabular}

*Grading according to house and Brackmann scale, "Classified according to Gardner Robertson scale 
recurrence rate. Sasaki and associates reported recurrence rates of $29 \%$ ( 5 of 17 patients) and 25\% ( 2 of 8 patients) for near-total and subtotal resection and no recurrences after total resection. ${ }^{[18]}$ Most authors reported a very low recurrence rate after complete tumor excision. ${ }^{[14]}$ Complete resection of these large lesions also helps us achieve maximum post-operative benefits in the form of improvement in Karnofsky performance score and overall quality of life. ${ }^{[16]}$

In our study, most of the patients were bedridden with poor KPS score at the time of presentation. In contrast to certain Western settings where signs of raised ICP and cerebellar dysfunction are rarely the presenting features ${ }^{[19]}$ many of our patients had clinical evidence of raised ICP (25\%) and/or cerebellar deficits (50\%) at the time of admission. It may be related to delayed presentation in our series. In our institute we do not have ultrasonic aspirator and nerve monitoring facilities. These tumors were operated with combined use of suction irrigation and bipolar coagulation. After initial arachnoid dissection internal decompression

Table 3: Grading of the tumors on the basis of MRI

\begin{tabular}{lll}
\hline Case & Hannover MRI grade & Side \\
\hline 1 & T4b & Right \\
2 & T4b & Right \\
3 & T4b & Left \\
4 & T4b & Right \\
5 & T4a & Left \\
6 & T4a & Left \\
7 & T4a & Right \\
8 & T4b & Left \\
9 & T4b & Left \\
10 & T4a & Right \\
11 & T4b & Left \\
12 & T4b & Left \\
\hline MRI: Magnetic resonance imaging &
\end{tabular}

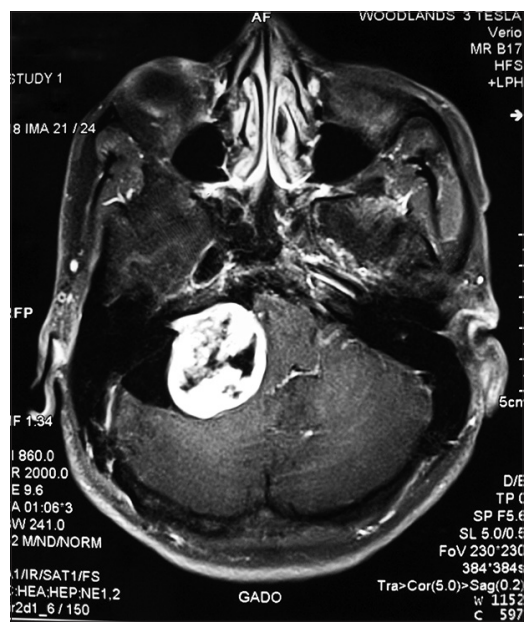

Figure 1: Pre-operative MRI brain $(P+C)$ of $32 \mathrm{M}$ having left sided giant vestibular schwannomas (Hannover stage $4 b$ ) was one using bipolar coagulation and suction irrigation. After maximum internal decompression the capsule was dissected from the brainstem and cranial nerves with microdissectors. In the initial four cases the surgeon became fatigued and the operation was done in two stages on two consecutive days. After overnight elective ventilation the patients were again operated the next morning. It was observed that the tumor could be dissected easily on the next day. This could be due to overnight brain relaxation and CSF pulsation which makes the tumor superficial and easier to dissect. So in the next eight cases we deliberately operated in two stages. Complete tumor excision was achieved in all the cases. This was ensured intraoperatively by patient dissection and exposure and confirmed at follow up with a contrast MRI. Anatomical integrity of the facial nerve could not be ascertained during the surgery due to lack of monitoring equipment. Facial nerve function showed improvement by at least 1 grade over a 6-month follow-up period. Quality of life showed improvement at follow up and all the patients showed improvement in their KPS score.

In the literature there are evidence of two-stage resections for giant vestibular schwannomas but in those cases the second operation was either by a different route ${ }^{[9]}$ or after a gap of at least a couple of weeks. ${ }^{[20]}$ Our study is unique in the sense that the second operation was performed on the very next day and complete resection was achieved without adding any morbidity and mortality. We do accept that our study sample size is small and the lack of modern neurosurgical equipment as well as severe economic constraints on the part of patients as well as government health care setups should not define our treatment strategies. However, we would emphasize that complete resection without deterioration of facial

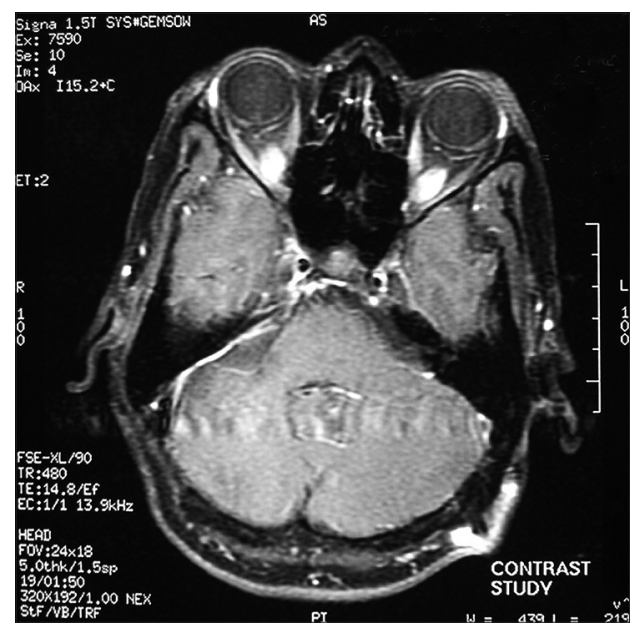

Figure 2: Post-operative image of the same patient at 6 months after surgery 
Table 4: Post-operative complications in the patients

\begin{tabular}{|c|c|c|c|c|c|c|c|c|}
\hline Case & CSF+leak & Hydrocephalus & Hematoma & $\begin{array}{c}\text { Facial nerve } \\
\text { dysfunction status }\end{array}$ & Meningitis & Siezures & $\begin{array}{l}\text { Lower cranial } \\
\text { nerve paresis }\end{array}$ & $\begin{array}{c}\text { Trigeminal } \\
\text { dysfunction }\end{array}$ \\
\hline$\overline{1}$ & - & - & - & $+(2)$ & - & - & - & - \\
\hline 2 & - & - & - & $+(4)$ & - & - & + & + \\
\hline 3 & - & - & - & $+(4)$ & - & - & - & - \\
\hline 4 & - & - & - & $+(3)$ & - & + & - & + \\
\hline 5 & - & - & - & $+(2)$ & - & - & + & - \\
\hline 6 & - & - & - & $+(3)$ & - & - & - & - \\
\hline 7 & - & - & - & $+(2)$ & + & - & - & + \\
\hline 8 & - & - & - & $+(2)$ & - & - & + & - \\
\hline 9 & - & - & - & $+(3)$ & + & - & - & + \\
\hline 10 & - & - & - & $+(2)$ & - & + & - & + \\
\hline 11 & - & - & - & $+(3)$ & - & - & - & - \\
\hline 12 & - & - & - & $+(2)$ & - & - & + & + \\
\hline
\end{tabular}

+Cereberospinal fluid, Complete removal was documented in the post-operative contrast MRI done at 6-month follow up, CSF = Cerebrospinal fluid

Table 5: Follow up analysis at 6 months

\begin{tabular}{lccccc}
\hline Case & $\begin{array}{c}\text { Facial } \\
\text { nerve } \\
\text { status at } \\
\mathbf{6} \text { months }\end{array}$ & Hearing & $\begin{array}{c}\text { Lower } \\
\text { cranial } \\
\text { nerve } \\
\text { dysfunction }\end{array}$ & $\begin{array}{c}\text { Trigeminal } \\
\text { nerve } \\
\text { dysfunction }\end{array}$ & $\begin{array}{c}\text { KPS } \\
\text { score at } \\
\mathbf{6} \text { months }\end{array}$ \\
\hline 1 & $+(1)$ & - & - & - & 80 \\
2 & $+(3)$ & - & - & - & 70 \\
3 & $+(3)$ & - & - & - & 80 \\
4 & $+(2)$ & - & - & - & 70 \\
5 & $+(1)$ & - & - & - & 80 \\
6 & $+(2)$ & - & - & - & 80 \\
7 & $+(1)$ & - & - & - & 70 \\
8 & $+(1)$ & - & - & - & 80 \\
9 & $+(2)$ & - & - & + & 70 \\
10 & $+(1)$ & - & - & + & 80 \\
11 & $+(2)$ & - & - & - & 80 \\
12 & $+(1)$ & - & - & - & 80 \\
\hline KPS $=$ Karnofky performance
\end{tabular}

nerve function of these giant vestibular schwannomas should be primary goal and that can be achieved in basic neurosurgical set ups.

\section{Conclusion}

Giant acoustic schwannomas can be safely resected completely by a staged resection on two consecutive days without any increased morbidity or mortality. This technique may be employed to achieve complete tumor resection in institutions which do not have advanced facilities like nerve monitoring or ultrasonic aspirator. Although there are no absolute indications for the staged resection of vestibular schwannomas, it should be considered an option for difficult cases.

\section{References}

1. Harner SG, Laws ER Jr. Clinical findings in patients with acoustic neurinoma. Mayo Clin Proc 1983;58:721-8.
2. Lanser MJ, Sussman SA, Frazer K. Epidemiology, pathogenesis, and genetics of acoustic tumors. Otolaryngol Clin North Am 1992;25:499-520.

3. Madjid S, Gerganov VM, Samii A. Functional outcome after complete surgical removal of giant vestibular schwannomas: Clinical article. J Neurosurg 2010;112:860-7.

4. Karnofsky DA, Burchenal JH, Armistead GC Jr, Southam CM, Bernstein JL, Craver LF, et al. Triethylenemelamine in the treatment of neoplastic disease; a compound with nitrogen-mustardlike activity suitable for oral and intravenous use. AMA Arch Intern Med 1951;87:477-516.

5. Seol HJ, Kim CH, Park CK, Kim CH, Kim DG, Chung YS, et al. Optimal extent of resection in vestibular schwannoma surgery: Relationship to recurrence and facial nerve preservation. Neurol Med Chir (Tokyo) 2006;46:176-81.

6. Ojemann RG, Martuza RL. Acoustic neuroma. In: Youmans JR, editor. Neurological Surgery. $3^{\text {rd }}$ ed. Philadelphia: WB Saunders; 1990. p. 3316-50.

7. Comey CH, Jannetta PJ, Sheptak PE, Joh HD, Burkhart LE. Staged removal of acoustic tumours: Techniques and lessons learned from a series of 83 patients. Neurosurgery 1995;37:915-21.

8. LeMay DR, Sun JK, Fishback D, Locke GE, Giannotta SL. Hypervascular acoustic neuroma. Neurol Res 1998;20:748-50.

9. Kim E, Nam SI. Staging in vestibular schwannoma surgery: A modified technique. J Korean Neurosurg Soc 2008;43:57-60.

10. Abe T, Izumiyama H, Imaizumi Y, Kobayashi S, Shimazu M, Sasaki K, et al. Staged resection of largehypervascular vestibular schwannomas in young adults. Skull Base 2001;11:199-206.

11. Kaylie, David M., Erik Gilbert, Michael A. Horgan, Johnny B. Delashaw, and Sean O. McMenomey. "Acoustic neuroma surgery outcomes." Otology \& neurotology 22, no. 5 (2001): 686-9.

12. House JW, Brackmann DE. Facial nerve grading system. Otolaryngol Head Neck Surg 1985;93:146-7.

13. Radiation Oncology/Toxicity/Inner Ear. Wikibooks, The Free Textbook Project.Available from: http://en.wikibooks.org/w/index. php?title=Radiation_Oncology $/$ Toxicity $/$ Inner_Earandoldid $=1569689$. [Last accessed on $2014 \mathrm{Feb} 13]$.

14. Matthies C, Samii M. Management of 1000 vestibular schwannomas (acoustic neuromas): Clinical presentation. Neurosurgery 1997;40:1-10.

15. Czosnyka Z, Czosnyka M, Richards H, Pickard JD. Chhabra hydrocephalus shunt: Lessons for gravitational valves. J Neurol Neurosurg Psychiatry 1998;65:406-7.

16. Misra BK, Purandare HR, Ved RS, Bagdia AA, Mare PB. Current treatment strategy in the management of vestibular schwannoma.Neurol India 2009;57:257-63.

17. Lunsford LD, Niranjan A, Flickinger JC, Maitz A, Kondziolka D. Radiosurgery of vestibular schwannomas: Summary of experience in 829 cases. J Neurosurg 2005;102 Suppl:195-9.

18. Sakaki S, Nakagawa K, Hatakeyama T, Murakami Y, Ohue S, Matsuoka K. Recurrence after incompletely resected acousticusneurinomas. Med J Osaka Univ 1991;40:59-66. 
19. Lanman TH, Brackmann DE, Hitselberger WE, Subin B. Report of 190 consecutive cases of large acoustic tumors (vestibular schwannoma) removed via the translabyrinthine approach. J Neurosurg 1999;90:617-23.

20. Ramina R, Coelho Neto M, Bordignon KC, Mattei T, Clemente R, Pires Aguiar PH. Treatment of large and giant residual and recurrent vestibular schwannomas. Skull Base 2007;17:109-17.
How to cite this article: Bandlish D, Biswas N, Deb S. Staging in giant vestibular schwannoma surgery: A two consecutive day technique for complete resection in basic neurosurgical setups. J Neurosci Rural Pract 2014;5:225-30.

Source of Support: Nil. Conflict of Interest: None declared.

\section{Author Help: Online submission of the manuscripts}

Articles can be submitted online from http://www.journalonweb.com. For online submission, the articles should be prepared in two files (first page file and article file). Images should be submitted separately.

\section{1) First Page File:}

Prepare the title page, covering letter, acknowledgement etc. using a word processor program. All information related to your identity should be included here. Use text/rtf/doc/pdf files. Do not zip the files.

\section{2) Article File:}

The main text of the article, beginning with the Abstract to References (including tables) should be in this file. Do not include any information (such as acknowledgement, your names in page headers etc.) in this file. Use text/rtf/doc/pdf files. Do not zip the files. Limit the file size to $1 \mathrm{MB}$. Do not incorporate images in the file. If file size is large, graphs can be submitted separately as images, without their being incorporated in the article file. This will reduce the size of the file.

3) Images:

Submit good quality color images. Each image should be less than $4096 \mathrm{~kb}(4 \mathrm{MB})$ in size. The size of the image can be reduced by decreasing the actual height and width of the images (keep up to about 6 inches and up to about $1800 \times 1200$ pixels). JPEG is the most suitable file format. The image quality should be good enough to judge the scientific value of the image. For the purpose of printing, always retain a good quality, high resolution image. This high resolution image should be sent to the editorial office at the time of sending a revised article.

4) Legends:

Legends for the figures/images should be included at the end of the article file. 